Wright State University

CORE Scholar

7-1-2008

\title{
Reproducible Increased Mg Incorporation and Large Hole Concentration in GaN Using Metal Modulated Epitaxy
}

\author{
Shawn D. Burnham \\ Gon Namkoong \\ David C. Look \\ Wright State University - Main Campus, david.look@wright.edu \\ Bruce Claflin \\ W. Alan Doolittle
}

Follow this and additional works at: https://corescholar.libraries.wright.edu/physics

Part of the Physics Commons

\section{Repository Citation}

Burnham, S. D., Namkoong, G., Look, D. C., Claflin, B., \& Doolittle, W. A. (2008). Reproducible Increased Mg Incorporation and Large Hole Concentration in GaN Using Metal Modulated Epitaxy. Journal of Applied Physics, 104 (2), 24902.

https://corescholar.libraries.wright.edu/physics/159

This Article is brought to you for free and open access by the Physics at CORE Scholar. It has been accepted for inclusion in Physics Faculty Publications by an authorized administrator of CORE Scholar. For more information, please contact library-corescholar@wright.edu. 


\title{
Reproducible increased Mg incorporation and large hole concentration in GaN using metal modulated epitaxy
}

\author{
Shawn D. Burnham, ${ }^{1, a)}$ Gon Namkoong, ${ }^{2}$ David C. Look, ${ }^{3}$ Bruce Clafin, ${ }^{3}$ and \\ W. Alan Doolittle $1, b)$ \\ ${ }^{1}$ School of Electrical and Computer Engineering, Georgia Institute of Technology, Atlanta, \\ Georgia 30332, USA \\ ${ }^{2}$ Electrical and Computer Engineering Department, Old Dominion University, Norfolk, \\ Virginia 23529, USA \\ ${ }^{3}$ Semiconductor Research Center, Wright State University, Dayton, Ohio 45435, USA
}

(Received 11 February 2008; accepted 7 May 2008; published online 17 July 2008)

\begin{abstract}
The metal modulated epitaxy (MME) growth technique is reported as a reliable approach to obtain reproducible large hole concentrations in $\mathrm{Mg}$-doped $\mathrm{GaN}$ grown by plasma-assisted molecular-beam epitaxy on $c$-plane sapphire substrates. An extremely Ga-rich flux was used, and modulated with the $\mathrm{Mg}$ source according to the MME growth technique. The shutter modulation approach of the MME technique allows optimal $\mathrm{Mg}$ surface coverage to build between MME cycles and $\mathrm{Mg}$ to incorporate at efficient levels in $\mathrm{GaN}$ films. The maximum sustained concentration of $\mathrm{Mg}$ obtained in $\mathrm{GaN}$ films using the MME technique was above $7 \times 10^{20} \mathrm{~cm}^{-3}$, leading to a hole concentration as high as $4.5 \times 10^{18} \mathrm{~cm}^{-3}$ at room temperature, with a mobility of $1.1 \mathrm{~cm}^{2} \mathrm{~V}^{-1} \mathrm{~s}^{-1}$ and a resistivity of $1.3 \Omega \mathrm{cm}$. At $580 \mathrm{~K}$, the corresponding values were $2.6 \times 10^{19} \mathrm{~cm}^{-3}, 1.2 \mathrm{~cm}^{2} \mathrm{~V}^{-1} \mathrm{~s}^{-1}$, and $0.21 \Omega \mathrm{cm}$, respectively. Even under strong white light, the sample remained $p$-type with little change in the electrical parameters. (C) 2008 American Institute of Physics.
\end{abstract}

[DOI: $10.1063 / 1.2953089]$

\section{INTRODUCTION}

Although $\mathrm{Mg}$ is the most successful $p$-type dopant for $\mathrm{GaN}$, high hole concentrations have been limited by many complications, including a low solubility of $\mathrm{Mg}$ into $\mathrm{GaN},{ }^{1}$ a tendency of $\mathrm{Mg}$ to accumulate and segregate at surfaces, ${ }^{2}$ formation of pyramid-shaped defects, ${ }^{3}$ a memory effect of $\mathrm{Mg}$ in a growth chamber, ${ }^{4,5}$ a high vapor pressure of $\mathrm{Mg}$ at low temperatures, ${ }^{6}$ a low sticking coefficient of $\mathrm{Mg}$ on $\mathrm{GaN}$, a deep ionization energy of $\mathrm{Mg}$ acceptors in $\mathrm{GaN},{ }^{7}$ unintentional hydrogen and oxygen doping, ${ }^{8,9}$ a significant compensation of $\mathrm{Mg}$ acceptors at high dopant concentrations, ${ }^{1}$ and a drastic dependence of incorporation upon the growth regime or III-V ratio. ${ }^{10,11}$ As a consequence, there is a narrow window of growth conditions, which yield electrically active p-type GaN. Furthermore, even low or moderate hole concentrations are often not consistently obtained and are difficult to reproduce due to the $\mathrm{Mg}$ incorporation sensitivity to growth conditions. These complications result in large and varied resistances and mobilities in GaN-based devices that rely on $p$-type layers. If hole carrier concentrations were to be increased, and $p$-type doping of GaN standardized, these devices could benefit from better performance and better reliability.

Despite the complications associated with $\mathrm{Mg}$-doped $\mathrm{GaN}$, current state-of-the-art reports show promising results and give a reference for comparison. $\mathrm{Mg}$ incorporation as determined by secondary ion mass spectroscopy (SIMS) has been reported to be as high as $8 \times 10^{20} \mathrm{~cm}^{-3}$ for metal or-

\footnotetext{
${ }^{a)}$ Present address: HRL Laboratories, LLC, Malibu, CA 90265.

b) Author to whom correspondence should be addressed. Electronic mail: alan.doolittle@ece.gatech.edu.
}

ganic chemical vapor deposition ${ }^{12}$ and $3.5 \times 10^{20} \mathrm{~cm}^{-3}$ for molecular beam epitaxy (MBE). ${ }^{13}$ However, above approximately $(2-3.5) \times 10^{20} \mathrm{~cm}^{-3}$, the $\mathrm{Mg}$ incorporation begins to decrease with increased $\mathrm{Mg}$ flux ${ }^{13}$ and inverts Ga-polar films to N-polar. ${ }^{14} M$-plane (10 $\left.\overline{1} 0\right)$ oriented substrates have been used to achieve a hole concentration as high as $p=7.2$ $\times 10^{18} \mathrm{~cm}^{-3}{ }^{15}$ Electrical characterization for current stateof-the-art films grown on $c$-plane substrates is shown in Table I. ${ }^{16-18}$ Reasonably high hole carrier concentrations are in the range of $(1-3) \times 10^{18} \mathrm{~cm}^{-3}$. However, hole concentrations have been reported to be as high as $6 \times 10^{18} \mathrm{~cm}^{-3}, 18$ although the carrier concentration was metastable and significantly reduced upon heating during measurement.

The metal modulated epitaxy (MME) growth technique was developed to specifically address reproducibility issues. ${ }^{19-22}$ The MME growth technique is characterized by a group-III (metal) flux much higher than the group-V source, which would normally lead to droplets. However, the metal shutter is modulated to avoid droplet buildup and therefore build and deplete the metal bilayer on the growth surface, yielding smoother surfaces, larger grain sizes, and better reproducibility. The optimal period and duty cycle of the shutter modulation can be determined by monitoring reflection

TABLE I. Electrical characteristics of state-of-the-art $\mathrm{Mg}$-doped $\mathrm{GaN}$ on $c$-plane substrates. $(*)$ The hole concentration reported was metastable and was reduced by half upon annealing.

\begin{tabular}{cccc}
\hline \hline Hole concentration $\left(10^{18} \mathrm{~cm}^{-3}\right)$ & 3 & 3 & $6^{*}$ \\
Mobility $\left(\mathrm{cm}^{2} \mathrm{~V}^{-1} \mathrm{~s}^{-1}\right)$ & 9 & 2 & 0.3 \\
Resistivity $(\Omega \mathrm{cm})$ & 0.23 & 1.04 & 3.47 \\
Reference & 16 & 17 & 18 \\
\hline \hline
\end{tabular}




\section{Unmodulated Droplet-free}

\section{Metal Modulated Epitaxy}
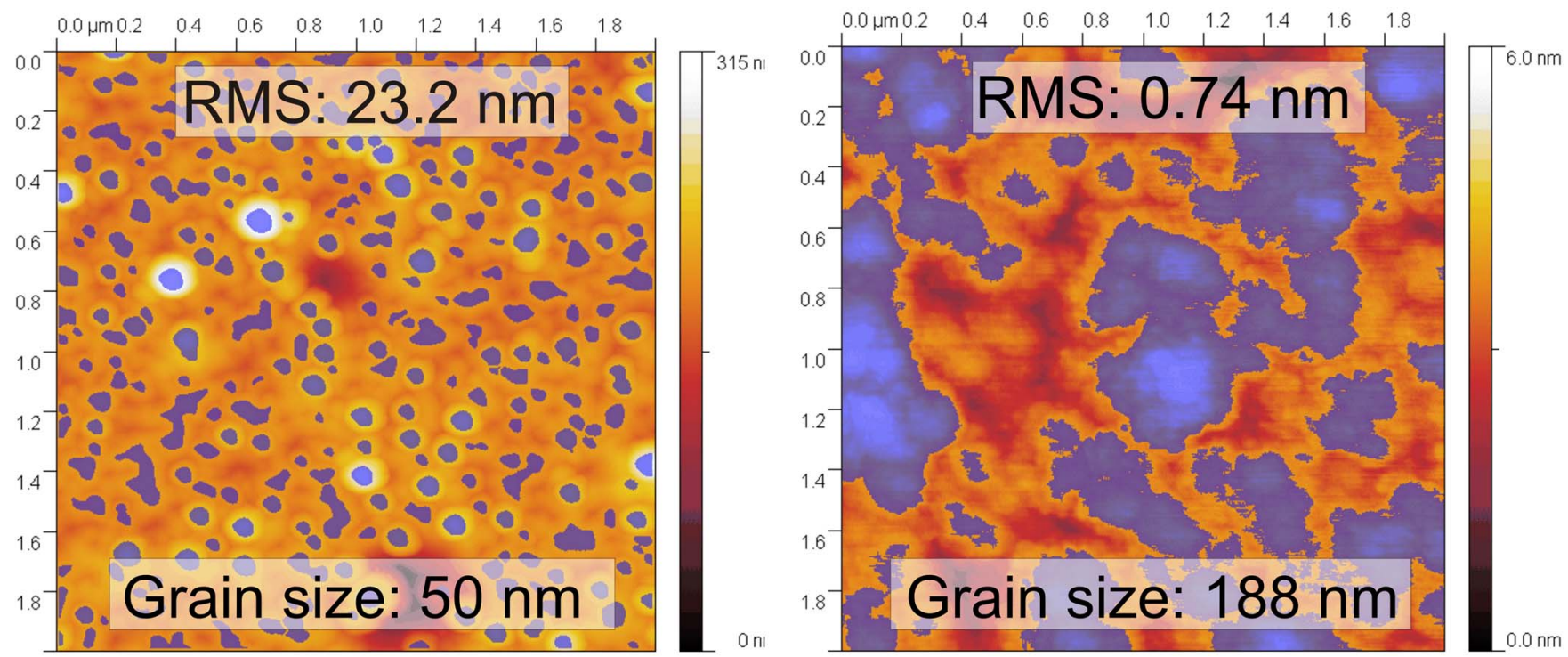

FIG. 1. (Color online) $2 \times 2 \mu \mathrm{m}^{2} \mathrm{AFM}$ scans of GaN samples grown using unmodulated droplet-free growth conditions and the MME growth technique, showing improved surface roughness and grain size as a result of metal-rich growth enhancing surface migration and lateral growth.

high energy electron diffraction intensity transients. ${ }^{21}$ However, until now the effects of a quantitative shutter modulation technique, such as MME, have only been reported for AlN. ${ }^{19-22}$ Other groups have used shutter modulation while growing GaN to improve intrarun surface uniformity, but the period and duty cycle were not experimentally determined, resulting in a significantly longer period than what was found necessary in the present work, and the effects on Mg-doped $\mathrm{GaN}$ were not discussed. ${ }^{23} \mathrm{GaN}$ surface morphology is similarly improved by the MME growth technique since it exhibits a laterally contracted metal bilayer much like AlN. ${ }^{24-27}$ Figure 1 shows $2 \times 2 \mu \mathrm{m}^{2}$ atomic force microscopy (AFM) scans of a GaN sample grown using unmodulated dropletfree growth conditions compared to a sample grown using the MME growth technique. Both samples were droplet-free after growth and were grown with a substrate temperature of $550{ }^{\circ} \mathrm{C}$ but used different $\mathrm{Ga}$ fluxes to avoid droplets with the unmodulated growth and to maintain droplet conditions with the MME growth. The height scale of each AFM data in Fig. 1 is different to exhibit grain size, and grains are highlighted. Surface rms roughness was reduced from 23 to $0.74 \mathrm{~nm}$, or a factor of 31 , and the average grain size was increased from 50 to $188 \mathrm{~nm}$, or $276 \%$, using the MME technique compared to unmodulated droplet-free growth. Furthermore, the percent variation of multiple GaN samples grown using the MME growth technique and same growth conditions was $18.7 \%$ for rms roughness and $1.57 \%$ for the average grain size, demonstrating the level of repeatability achieved with the MME growth technique. However, along with improved $\mathrm{GaN}$ morphology, $\mathrm{Mg}$ incorporation could also be affected by the shutter transitions. Therefore, this paper will report the results of $\mathrm{Mg}$-doped $\mathrm{GaN}$ using the MME growth technique.

\section{EXPERIMENTAL PROCEDURES}

The presented epitaxial films were grown in a Riber 32 MBE system with traditional effusion cells for $\mathrm{Ga}$ and $\mathrm{Al}$. The Mg source was supplied using a Veeco 200cc Corrosive Series Valved Cracker, as described elsewhere. ${ }^{10,28-30} \mathrm{~A}$ Veeco UNI-Bulb radio-frequency plasma was used for the nitrogen source with $350 \mathrm{~W}$ of input power and an input molecular flow rate of 1.3 SCCM (SCCM denotes cubic centimeters per minute at standard temperature and pressure). All expitaxial films in the present experiments were grown on [0001] basal $c$-plane oriented sapphire substrates, approximately $430 \mu \mathrm{m}$ thick, with a polished growth surface and rough backside. Molybdenum was deposited on the rough backside to promote thermal absorption. To maintain high purity in the growth environment and minimize contamination, all samples were chemically cleaned to remove organics before entering the vacuum system. The samples were cleaned with a hot piranha etch, which consisted of a 4:1 mixture of $\mathrm{H}_{2} \mathrm{SO}_{4}: \mathrm{H}_{2} \mathrm{O}_{2}$ heated to approximately $90{ }^{\circ} \mathrm{C}$ for $10 \mathrm{~min}^{31}$ They were rinsed with de-ionized (DI) water, dried with a nitrogen spray gun, and mounted onto a Veeco UNI-Block sample holder with custom-made molybdenum (Mo) retaining rings and spring plates. To further clean the samples they were then loaded into the high-vacuum introduction chamber, where they were outgassed at $700{ }^{\circ} \mathrm{C}$ for 10 min. $^{31,32}$

To minimize the adverse effects of mismatch, lowtemperature nitridation and high-temperature AlN buffer layers were grown before growing the GaN films. ${ }^{33}$ Nitridation of the sapphire substrates was done at $200{ }^{\circ} \mathrm{C}$ for $1 \mathrm{~h} .{ }^{34}$ The AlN buffer layer was grown using the MME growth technique $^{22}$ with a substrate temperature of $800{ }^{\circ} \mathrm{C}$, an $\mathrm{Al}$ cell temperature of $1150{ }^{\circ} \mathrm{C}\left[3.85 \times 10^{-7}\right.$ Torr, beam equiva- 


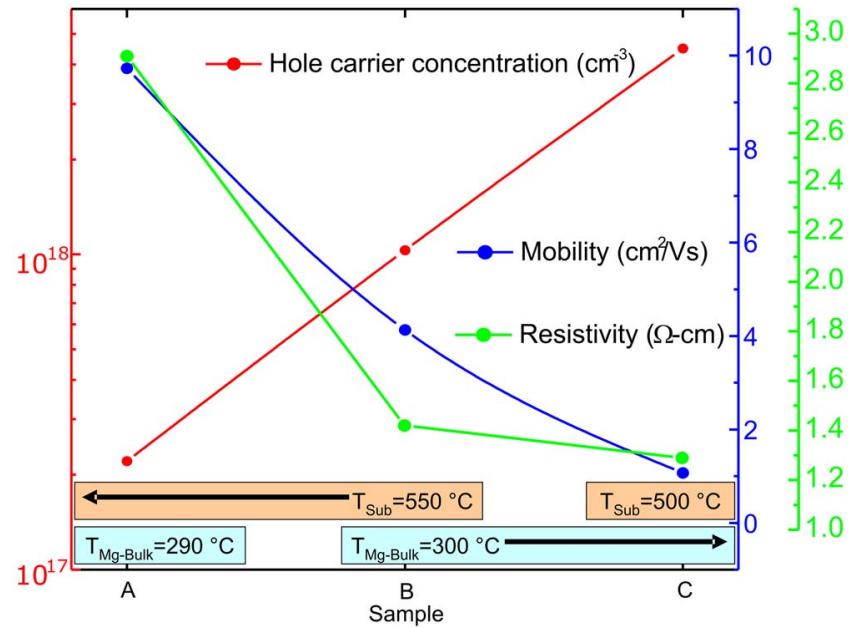

FIG. 2. (Color online) Electrical characterization values of Mg-doped GaN films. From left to right: film grown with $550{ }^{\circ} \mathrm{C}$ substrate temperature and $290{ }^{\circ} \mathrm{C} \mathrm{Mg}$ bulk temperature, sample grown with the same substrate temperature but with a $300{ }^{\circ} \mathrm{C} \mathrm{Mg}$ bulk temperature, and sample grown with the same $\mathrm{Mg}$ bulk temperature but with a $500{ }^{\circ} \mathrm{C}$ substrate temperature.

lent pressure (BEP)], and a modulation of $10 \mathrm{~s}$ for the shutter closed and open time. This resulted in a growth rate of approximately $0.5 \mu \mathrm{m} / \mathrm{h}$. Therefore, for a target AlN buffer layer thickness of $100 \mathrm{~nm}$, the AlN film was grown for approximately $12 \mathrm{~min}$. For the electrically active $\mathrm{Mg}$-doped $\mathrm{GaN}$ epitaxial films, the substrate temperature was between 500 and $550{ }^{\circ} \mathrm{C}$. Furthermore, the $\mathrm{Mg}$ bulk temperature was between 290 and $300{ }^{\circ} \mathrm{C}$. The Ga cell temperature was $990{ }^{\circ} \mathrm{C}\left(5.32 \times 10^{-7}\right.$ Torr, BEP $)$, the $\mathrm{Mg}$ valve tip temperature was $900{ }^{\circ} \mathrm{C}$, and the valve position was set to the open position of 100 mils, in the range of 0-300 mils for fully closed to fully open. To implement the MME growth technique, both the $\mathrm{Ga}$ and $\mathrm{Mg}$ shutters were modulated using simultaneous $10 \mathrm{~s}$ with shutters open and $10 \mathrm{~s}$ with shutters closed.

\section{DISCUSSION}

Electrical characterization of the electrically active films was done using the van der Pauw method for resistivity and Hall coefficient measurements, ${ }^{35,36}$ and the data are shown in Fig. 2. Hole carrier concentration ranged from 2.0 $\times 10^{17}$ to $4.5 \times 10^{18} \mathrm{~cm}^{-3}$, with corresponding mobility from 9.7 to $1.1 \mathrm{~cm}^{2} \mathrm{~V}^{-1} \mathrm{~s}^{-1}$ and resistivity from 2.9 to $1.3 \Omega \mathrm{cm}$. The average percentage variation of samples grown with the same target electrical properties was $7.7 \%$ for hole concentration, $23.6 \%$ for mobility, and $21.4 \%$ for resistivity. The higher hole concentration was achieved with a substrate temperature lower than that used for the other two Mg-doped GaN samples, which indicates that a lower substrate temperature allows incorporation of more $\mathrm{Mg}$ because of the high $\mathrm{Mg}$ vapor pressure. The unusually large hole carrier concentration of $4.5 \times 10^{18} \mathrm{~cm}^{-3}$ can be ascribed not only to the low growth temperatures, but also to the improved crystal quality from the MME technique and an enhanced $\mathrm{Mg}$ incorporation by shutter modulation, described later. Furthermore, attempting to repeat the highest hole concentration resulted in remarkably good repeatability, even better than av-

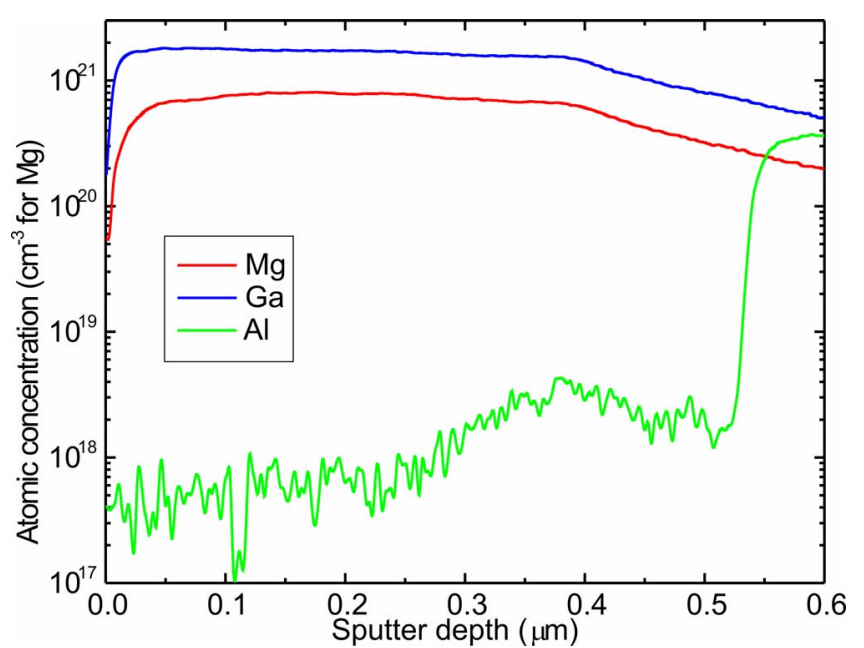

FIG. 3. (Color online) SIMS data for Mg-doped GaN sample with constant doping to illustrate uniform doping using the MME growth technique with high $\mathrm{Mg}$ incorporation. The average incorporation level of $\mathrm{Mg}$ is 7 $\times 10^{20} \mathrm{~cm}^{-3}$. $\mathrm{Mg}, \mathrm{Ga}$, and $\mathrm{Al}$ signals mix at a depth of approximately $0.4 \mu \mathrm{m}$ because of crater rounding at the film interface.

erages presented above. For samples grown two weeks apart, with $\mathrm{Ga}$ and $\mathrm{Mg}$ fluxes varied slightly, hole concentrations were $4.51 \times 10^{18}$ and $4.42 \times 10^{18} \mathrm{~cm}^{-3}$, or less than $2 \%$ variation, regardless of sample thickness $(0.38$ and $0.52 \mu \mathrm{m}$, respectively). This enhanced repeatability is likely due to the incorporation limited growth dictated by the MME growth technique and the subsequent inability of $\mathrm{Mg}$ to build up to a surface concentration high enough to result in inversion of the polarity and reduction in incorporation. Further Hall coefficient measurements were taken at higher temperatures and at room temperature with variable illumination to observe the effect on electrical characteristics. At $580 \mathrm{~K}$, the hole concentration was increased to $2.6 \times 10^{19} \mathrm{~cm}^{-3}$, with an associated mobility of $1.2 \mathrm{~cm}^{2} \mathrm{~V}^{-1} \mathrm{~s}^{-1}$ and resistivity of $0.21 \Omega \mathrm{cm}$. Finally, strong white light produced very little change in the electrical parameters at room temperature. These results confirm the consistent $p$-type characteristic and nature of this material.

According to SIMS, enhanced $\mathrm{Mg}$ incorporation was demonstrated with a substrate temperature of $550{ }^{\circ} \mathrm{C}$, and a $\mathrm{Mg}$ bulk temperature of $330^{\circ} \mathrm{C}$, although the $\mathrm{Mg}$ incorporation was much higher than that found for films with large hole concentrations. The resulting material with the highest $\mathrm{Mg}$ incorporation was highly resistive, beyond the measurement capability of the Hall measurement system. The uniformity of $\mathrm{Mg}$ doping is illustrated in Fig. 3, which shows the SIMS data for the bulk Mg-doped GaN sample with a consistent $\mathrm{Mg}$ incorporation level of approximately 7 $\times 10^{20} \mathrm{~cm}^{-3}$, without abrupt $\mathrm{Mg}$ incorporation levels despite the shutter modulation approach. In the figure, the deviations at the extremities are due to non-steady-state surface effects $^{37}$ and the mixing of secondary ion species at the matrix change (substrate interface) at approximately $0.4 \mu \mathrm{m}$ due to a nonflat crater bottom. In previous reports without the MME growth technique, $\mathrm{Mg}$ concentrations were not sustainable above approximately $3 \times 10^{20} \mathrm{~cm}^{-3}$ but were decreased with further $\mathrm{Mg}$ exposure or increased $\mathrm{Mg}$ fluxes ${ }^{13}$ as a result of surface segregation effects. ${ }^{2}$ It was found that 
higher Mg fluxes eventually saturate the GaN surface with $\mathrm{Mg}$, defining the saturation limit of $\mathrm{Mg}$ on $\mathrm{GaN}$. As $\mathrm{Mg}$ continues to accumulate on the surface of $\mathrm{GaN}$ beyond the saturation limit, Ga-polar films eventually invert to N-polar $\mathrm{GaN}^{14}$ which results in the reduction of $\mathrm{Mg}$ incorporation. ${ }^{2}$ However, the MME growth technique results in sustained higher Mg incorporation levels, unlike that experienced with the traditional growth techniques.

This enhanced Mg incorporation effect of MME can be examined in the two distinct growth regimes below and above the $\mathrm{Mg}$ saturation limit of $\mathrm{Mg}$ and can be related to established theoretical models. ${ }^{38}$ However, the established theoretical models are presently incapable of examining the lowest $\mathrm{Mg}$ concentration cases below the critical $\mathrm{Mg}$ flux because of computational limitations. Thus, the following analysis is based on phenomenological surface physics. Experimentally, below the saturation limit of $\mathrm{Mg}$ in $\mathrm{GaN}$, the level of $\mathrm{Mg}$ doping is consistent between the unmodulated and MME growth techniques, and it is likely that all deposited $\mathrm{Mg}$ are either consumed or desorbed between MME cycles. However, at the saturation limit and above, where computational aids can be validated, there are drastic differences between the unmodulated and MME growth techniques. For Ga-polar material grown with N-rich conditions, it has been shown ${ }^{38}$ that stable configurations of $\mathrm{Mg}$ in the second bilayer of the GaN crystal lattice form above $0.5 \mathrm{ML}$ (monolayers) of $\mathrm{Mg}$ and that stable configurations exist without defect generation up to $1 \mathrm{ML} \mathrm{Mg}$. However, in all of the stable configurations, the majority of $\mathrm{Mg}$ exists on the surface. ${ }^{38}$ Furthermore, in the intermediate Ga-rich regime with a $\mathrm{Ga}$ bilayer, $\mathrm{Mg}$ atoms will replace $\mathrm{Ga}$ atoms in the bilayer to form $\mathrm{Mg}$ concentration in the metal bilayer. The resulting $\mathrm{Mg}$ concentration in the bilayer forms a stable configuration at the interface between the bilayer and the $\mathrm{GaN}$ film between 0.5 and $1 \mathrm{ML} \mathrm{Mg}$, with $\mathrm{Mg}$ in the second bilayer of the GaN crystal lattice. In other words, negligible amounts of $\mathrm{Mg}$ are incorporated into $\mathrm{GaN}$ below $0.5 \mathrm{ML}$ $\mathrm{Mg}$, and while some $\mathrm{Mg}$ is incorporated into the GaN film during growth above $0.5 \mathrm{ML} \mathrm{Mg,} \mathrm{Mg}$ also forms stable structures on the sample surface. Above $1 \mathrm{ML} \mathrm{Mg}$, the local polarity is changed from Ga-polar to $\mathrm{N}$-polar, and $\mathrm{Mg}$ incorporation is drastically reduced.

Therefore, a $\mathrm{Mg}$ adsorbed atom (adatom) is able to remain on the $\mathrm{GaN}$ surface in a stable configuration beyond the period of MME when Mg surface coverage is below 0.5 ML $\mathrm{Mg}$. The Mg surface coverage will then continue to build up to higher levels with further cycles of MME until a coverage of $0.5 \mathrm{ML} \mathrm{Mg}$ is reached when some of the $\mathrm{Mg}$ will be incorporated into the film. The unincorporated $\mathrm{Mg}$ will remain on the surface in a stable configuration and continue to supply $\mathrm{Mg}$ to the growing $\mathrm{GaN}$ film, as with the case of the closed shutter with the MME technique, and the film will remain Ga-polar as long as the surface coverage does not reach or exceed $1 \mathrm{ML} \mathrm{Mg}$. This would be indicated by a drastic reduction in $\mathrm{Mg}$ incorporation with the change to $\mathrm{N}$-polar, which is not observed in Fig. 3, so it is believed that this limit is never exceeded in the current MME experiments. Therefore, the MME growth technique is able to maintain a sufficient Mg surface coverage to incorporate high Mg con- centrations without exceeding the surface concentration limit and therefore inverting the polarity to $\mathrm{N}$-polar. The ability of MME to maintain optimal growth conditions is a result of the shutter modulation approach, which allows Mg surface coverage to build between MME cycles and continuously incorporate at the optimal level.

\section{CONCLUSION}

The MME growth technique has been shown to improve the morphology of both AlN (Ref. 21) and GaN due to the increased adatom migration and improved lateral growth. For GaN grown with MME, grain size was increased to nearly $200 \mathrm{~nm}$ with percentage variation of less than $1.6 \%$. The effect of the shutter modulation technique on $\mathrm{Mg}$ incorporation was observed for $\mathrm{Mg}$-doped $\mathrm{GaN}$. Consistent electrically active $\mathrm{Mg}$-doped $\mathrm{GaN}$ was achieved with hole concentrations up to $4.5 \times 10^{18} \mathrm{~cm}^{-3}$, with an average percentage variation of less than $8 \%$. The SIMS analysis shows that $\mathrm{Mg}$ doping is uniform and consistent throughout the bulk of the film despite the transient shutter modulation, with concentrations up to $7 \times 10^{20} \mathrm{~cm}^{-3}$. Previous studies on the energetics of $\mathrm{Mg}$ incorporation on $\mathrm{GaN}$ were used to explain the mechanism of increased and repeatable $\mathrm{Mg}$ incorporation and hole carrier concentration. With the increased hole carrier concentration and improved repeatability offered by the MME growth technique, GaN-based devices, which rely on $p$-type layers, can benefit from the increased performance and improved reliability.

\section{ACKNOWLEDGMENTS}

The authors would like to acknowledge funding for this work from AFOSR MURI monitored by Dr. Donald Silversmith and ONR Basic Science Grants monitored by Dr. Paul Maki.

${ }^{1}$ C. G. Van De Walle, C. Stampfl, and J. Neugebauer, J. Cryst. Growth 189-190, 5050 (1998).

${ }^{2}$ A. J. Ptak, T. H. Myers, L. T. Romano, C. G. Van De Walle, and J. E. Northrup, Appl. Phys. Lett. 78, 285 (2001).

${ }^{3}$ P. Vennegues, M. Benaissa, B. Beaumont, E. Feltin, P. De Mierry, S. Dalmasso, M. Leroux, and P. Gibart, Appl. Phys. Lett. 77, 880 (2000).

${ }^{4}$ Y. Ohba and A. Hatano, J. Cryst. Growth 145, 214 (1994).

${ }^{5}$ B. Y. Ber, Y. A. Kudriavtsev, A. V. Merkulov, S. V. Novikov, D. E. Lacklison, J. W. Orton, T. S. Cheng, and C. T. Foxon, Semicond. Sci. Technol. 13, 71 (1998).

${ }^{6}$ D. R. Lide, CRC Handbook of Chemistry and Physics, 78th ed. (CRC, Boca Raton, FL, 1997).

${ }^{7}$ I. Akasaki, H. Amano, M. Kito, and K. Hiramatsu, J. Lumin. 48-49, 666 (1991).

${ }^{8}$ J. Neugebauer and C. G. Vandewalle, Phys. Rev. Lett. 75, 4452 (1995).

${ }^{9}$ B. C. Chung and M. Gershenzon, J. Appl. Phys. 72, 651 (1992).

${ }^{10}$ S. D. Burnham, W. A. Doolittle, G. Namkoong, and W. Henderson, Mater. Res. Soc. Symp. Proc. 798, 479 (2004).

${ }^{11}$ I. Berishev, E. Kim, A. Fartassi, M. Sayhi, and A. Bensoula, J. Vac. Sci. Technol. A 17, 2166 (1999).

${ }^{12}$ P. Kozodoy, H. L. Xing, S. P. DenBaars, U. K. Mishra, A. Saxler, R. Perrin, S. Elhamri, and W. C. Mitchel, J. Appl. Phys. 87, 1832 (2000).

${ }^{13}$ G. Namkoong, W. A. Doolittle, and A. S. Brown, Appl. Phys. Lett. 77, 4386 (2000).

${ }^{14}$ V. Ramachandran, R. M. Feenstra, W. L. Sarney, L. Salamanca-Riba, J. E. Northrup, L. T. Romano, and D. W. Greve, Appl. Phys. Lett. 75, 808 (1999).

${ }^{15}$ M. McLaurin, T. E. Mates, and J. S. Speck, Appl. Phys. Lett. 86, 262104 (2005). 
${ }^{16}$ S. Nakamura, M. Senoh, and T. Mukai, J. Visual Commun. Image Represent 30, L1708 (1991).

${ }^{17}$ A. Bhattacharyya, W. Li, J. Cabalu, T. D. Moustakas, D. J. Smith, and R. L. Hervig, Appl. Phys. Lett. 85, 4956 (2004).

${ }^{18}$ H. M. Ng, D. Doppalapudi, D. Korakakis, R. Singh, and T. D. Moustakas, J. Cryst. Growth 190, 349 (1998).

${ }^{19}$ S. D. Burnham and W. A. Doolittle, in 33rd Conference on the Physics and Chemistry of Semiconductor Interfaces, Cocoa Beach, FL, 2006.

${ }^{20}$ S. D. Burnham and W. A. Doolittle, J. Vac. Sci. Technol. B 24, 2100 (2006).

${ }^{21}$ S. D. Burnham, G. Namkoong, K.-K. Lee, and W. A. Doolittle, in 24th North American Conference on Molecular Beam Epitaxy, Durham, NC 2006.

${ }^{22}$ S. D. Burnham, G. Namkoong, K.-K. Lee, and W. A. Doolittle, J. Vac. Sci. Technol. B 25, 1009 (2007).

${ }^{23}$ C. Poblenz, P. Waltereit, and J. S. Speck, J. Vac. Sci. Technol. B 23, 1379 (2005).

${ }^{24}$ J. E. Northrup, J. Neugebauer, R. M. Feenstra, and A. R. Smith, Phys. Rev. B 61, 9932 (2000).

${ }^{25}$ A. R. Smith, R. M. Feenstra, D. W. Greve, M. S. Shin, M. Skowronski, J. Neugebauer, and J. E. Northrup, Surf. Sci. 423, 70 (1999).

${ }^{26}$ C. Adelmann, J. Brault, G. Mula, B. Daudin, L. Lymperakis, and J. Neugebauer, Phys. Rev. B 67, 165419 (2003).
${ }^{27}$ C. D. Lee, Y. Dong, R. M. Feenstra, J. E. Northrup, and J. Neugebauer, Phys. Rev. B 68, 205317 (2003).

${ }^{28}$ S. D. Burnham, G. Namkoong, and W. A. Doolittle, in Workshop on Compound Semiconductor Materials and Devices, Miami, FL, 2005.

${ }^{29}$ S. D. Burnham, G. Namkoong, W. Henderson, and W. A. Doolittle, in 2003 Materials Research Society Fall Meeting, Boston, MA, 2003, pp. Y8.11.1-Y8.11.6.

${ }^{30}$ S. D. Burnham, G. Namkoong, W. Henderson, and W. A. Doolittle, J. Cryst. Growth 279, 26 (2005).

${ }^{31}$ Z. Liu, Y. Sun, F. Machuca, P. Pianetta, and W. E. Spicer, J. Vac. Sci. Technol. B 21, 1953 (2003).

${ }^{32}$ F. Machuca, Z. Liu, Y. Sun, P. Pianetta, W. E. Spicer, and R. F. W. Pease, J. Vac. Sci. Technol. A 20, 1784 (2002).

${ }^{33}$ G. Namkoong, W. A. Doolittle, A. S. Brown, M. Losurdo, M. M. Giangregorio, and G. Bruno, J. Cryst. Growth 252, 159 (2003).

${ }^{34}$ G. Namkoong, W. A. Doolittle, A. S. Brown, M. Losurdo, P. Capezzuto, and G. Bruno, J. Appl. Phys. 91, 2499 (2002).

${ }^{35}$ L. J. van der Pauw, Philips Res. Rep. 13, 1 (1958).

${ }^{36}$ L. J. van der Pauw, Philips Tech. Rev. 20, 220 (1958).

${ }^{37}$ Z. L. Liau, J. W. Mayer, W. L. Brown, and J. M. Poate, J. Appl. Phys. 49, 5295 (1978)

${ }^{38}$ Q. A. Sun, A. Selloni, T. H. Myers, and W. A. Doolittle, Phys. Rev. B, 73, 155337 (2006) 